\title{
Expression of Osteopontin in oesophageal squamous cell carcinoma
}

\section{Y Kita*,', S Natsugoe', H Okumura', M Matsumoto', Y Uchikado', T Setoyama', T Owaki', S Ishigami' and T Aikou'}

'Department of Surgical Oncology and Digestive Surgery, Field of Oncology, Course of Advanced Therapeutics, Graduate School of Medical and Dental Science, Kagoshima University, Sakuragaoka 8-35-1, Kagoshima 890-8520, Japan

\begin{abstract}
Osteopontin is a multifunctional $34 \mathrm{kDa}$ extracellular matrix protein with a cell-binding domain. It is involved cell adhesion and cell migration and is therefore considered to influence tumorigenesis and/or metastasis. The purpose of the present study was to evaluate the clinical significance of Osteopontin expression in oesophageal squamous cell carcinoma (ESCC). In the present study, we immunohistochemically investigated the relationship between Osteopontin expression and clinicopathological factors including prognosis in surgical specimens of primary tumours in 175 patients with ESCC. Osteopontin was expressed in $48 \%$ of 175 patients. Osteopontin expression was significantly correlated with lymph node metastasis, lymphatic invasion, and stage ( $P=0.00$ I 5, 0.037 and 0.033, respectively). Tumours with expressing Osteopontin exhibited more lymph node metastasis, lymphatic invasion and advanced stage than the tumour with negative Osteopontin expression. Five-year survival rate was better in patients with negative Osteopontin expression than in those with positive Osteopontin expression $(P=0.035)$. However, multivariate analysis revealed that Osteopontin expression was not an independent prognostic factor. As our findings suggest that Osteopontin may play an important role in progress of ESCC, the evaluation of Osteopontin expression is useful for predicting the malignant properties of ESCC.
\end{abstract}

British Journal of Cancer (2006) 95, 634-638. doi:I0.1038/sj.bjc.6603296 www.bjcancer.com

Published online I August 2006

(c) 2006 Cancer Research UK

Keywords: osteopontin; oesophageal cancer; immunohistochemical staining; prognosis; lymph node metastasis

Osteopontin is a $34 \mathrm{kDa}$ extracellular matrix protein with a cellbinding domain (Sodek et al, 2000) and was originally identified as a major component of the noncollagenous organic bone matrix. It secretes adhesive glycoprotein and seems to be involved in osteoblast differentiation, bone formation and remodelling of mineralised tissue (Reinholt et al, 1990; Giachelli and Steitz, 2000). Other molecules which share this domain include fibronectin, vitronectin and a variety of other extracellular proteins that bind members of the integrin family of cell surface receptors (Varner and Cheresh, 1996). The expression of Osteopontin has subsequently been demonstrated in a wide range of normal human tissue and body fluid such as osteoblasts, arterial smooth muscle cells, leukocytes, activated macrophages and T cells (Coppola et al, 2004), and epithelia of the gastro-intestinal tract (Brown et al, 1992; Brown et al, 1994). It is a multifunctional protein involved in cell adhesion and cell migration, and has been shown to play important roles in tumorigenesis, tumour invasion, metastasis and prognosis among patients with breast (Tuck et al, 1998), lung (Zhang et al, 2001; Donati et al, 2005), prostate (Thalmann et al, 1999), gastric (Ue et al, 1998) and colon cancer (Agrawal et al, 2002).

*Correspondence: Dr Y Kita;

E-mail: north-y@m.kufm.kagoshima-u.ac.jp

Received 23 February 2006; revised 14 June 2006; accepted 29 June 2006; published online I August 2006
Oesophageal squamous cell carcinoma (ESCC) is one of the most aggressive carcinomas in the gastrointestinal tracts. Studies of various biological factors affecting the malignant potential of ESCC have been performed. However, the expression of Osteopontin in ESCC has not been evaluated. The aims of this retrospective study were to examine the expression of Osteopontin in surgical specimens of ESCC and to evaluate whether this is useful in predicting outcome.

\section{MATERIALS AND METHODS}

\section{Patients and specimens}

Subjects were 175 patients with ESCC (160 men and 15 women) who underwent oesophagectomy with lymph node dissection between 1987 and 1998 at Kagoshima University Hospital, Japan. The median age of the patients was 64 years (range 36-83 years). None of these patients underwent endoscopic mucosal resection, palliative resection, preoperative chemotherapy and/or radiotherapy, and none of them had synchronous or metachronous cancer in other organs. Specimens of cancer tissues and noncancerous adjacent tissue were collected from patients after informed consent had been obtained in accordance with the institutional guidelines of our hospital. Using the tumour node metastasis classification of the International Union Against Cancer (Sobin and Fleming, 1997), all of the M1 tumours exhibited distant lymph node metastases. Clinicopathologic data of patients in this 
Table I Relationship between Osteopontin expression and clinicopathological findings

\begin{tabular}{|c|c|c|c|c|}
\hline & \multirow[b]{2}{*}{$\begin{array}{c}\text { Total } \\
(n=175)\end{array}$} & \multicolumn{2}{|c|}{ Osteopontin } & \multirow[b]{2}{*}{$P$-value } \\
\hline & & $\begin{array}{c}\text { Positive } \\
n=84 \\
(48.0 \%)\end{array}$ & $\begin{array}{c}\text { Negative } \\
n=91 \\
(52.0 \%)\end{array}$ & \\
\hline \multicolumn{5}{|l|}{ Age } \\
\hline Mean & & 62.8 & 63.3 & \multirow{2}{*}{0.7041} \\
\hline $\mathrm{SD}^{\mathrm{a}}$ & & 8.0 & 9.8 & \\
\hline \multicolumn{5}{|l|}{ Gender } \\
\hline Male & 160 & $80(87.9)$ & $80(95.2)$ & \multirow[t]{2}{*}{0.0775} \\
\hline Female & 15 & $11(12.1)$ & $4(4.8)$ & \\
\hline \multicolumn{5}{|c|}{ Tumour location } \\
\hline Upper & 23 & $15(16.5)$ & $8(9.5)$ & \multirow[t]{3}{*}{0.1611} \\
\hline Middle & 92 & $50(55.0)$ & $42(50.0)$ & \\
\hline Lower & 60 & $26(28.5)$ & $34(40.5)$ & \\
\hline \multicolumn{5}{|l|}{ Histology } \\
\hline Well & 62 & $29(34.5)$ & $33(36.3)$ & \multirow{3}{*}{0.5678} \\
\hline Moderate & 85 & $39(46.6)$ & $46(50.5)$ & \\
\hline Poor & 28 & $16(19.1)$ & $12(13.8)$ & \\
\hline \multicolumn{5}{|c|}{ pT } \\
\hline pTI & 58 & $24(28.6)$ & $34(37.4)$ & \multirow[t]{4}{*}{0.4339} \\
\hline pT2 & 22 & $9(10.7)$ & $13(14.3)$ & \\
\hline pT3 & 66 & $35(41.7)$ & $31(34.0)$ & \\
\hline PT4 & 29 & $16(19.0)$ & $13(14.3)$ & \\
\hline \multicolumn{5}{|l|}{$p N$} \\
\hline $\mathrm{pNO}$ & 78 & $27(32.1)$ & $5 \mid(56.0)$ & \multirow[t]{2}{*}{0.0015} \\
\hline $\mathrm{pNI}$ & 97 & 57 (77.9) & $40(44.0)$ & \\
\hline \multicolumn{5}{|l|}{$p M$} \\
\hline pMO & 131 & $57(67.9)$ & $74(81.3)$ & \multirow[t]{2}{*}{0.1398} \\
\hline pMI & 44 & $27(32.1)$ & $17(18.7)$ & \\
\hline \multicolumn{5}{|l|}{ Stage } \\
\hline 1 & 41 & $14(16.7)$ & $27(29.7)$ & \multirow[t]{5}{*}{0.0333} \\
\hline$\| \mathrm{A}$ & 31 & $12(14.2)$ & $19(20.9)$ & \\
\hline$\| B$ & 21 & $14(16.7)$ & $7(7.7)$ & \\
\hline III & 38 & $17(20.2)$ & $21(23.1)$ & \\
\hline IV & 44 & $27(32.2)$ & $17(18.6)$ & \\
\hline \multicolumn{5}{|c|}{ Lymphatic invasion } \\
\hline Negative & 66 & $25(29.8)$ & $4 \mid(45.1)$ & \multirow[t]{2}{*}{0.0375} \\
\hline Positive & 109 & $59(70.2)$ & $50(54.9)$ & \\
\hline \multicolumn{5}{|c|}{ Venous invasion } \\
\hline Negative & 125 & $52(61.9)$ & $66(72.5)$ & \multirow[t]{2}{*}{0.1339} \\
\hline Positive & 50 & $32(38.1)$ & $25(27.5)$ & \\
\hline
\end{tabular}

${ }^{\mathrm{a} S t a n d a r d ~ d e v i a t i o n}$

study were shown in Table 1 . All patients were followed-up after discharge, with X-ray examination and tumour marker assays (squamous cell carcinoma antigen and carcinoembryonic antigen) every 1-3 months, computed tomography every 3-6 months, and ultrasonography every 6 months. Bronchoscopy and endoscopy were performed when necessary. Postoperative follow-up data were obtained from all patients, with a median follow-up period of 28 months (range, 1-175 months).

\section{Immunohistochemical staining and evaluation}

Specimens were cut into $3-\mu$ m-thick sections, which were mounted on glass slides. Immunohistochemical staining was carried out using the avidin-biotin-peroxidase complex method (Vectastatin Elite ABC Kit; Vector, Burlingame, CA, USA), following the manufacturer's instructions. Briefly, the immunostaining was performed manually at room temperature. Sections were deparaffinised in xylene and dehydrated in ethanol, endogenous peroxidase activity was blocked by incubating sections for $10 \mathrm{~min}$ in $3 \%$ hydrogen peroxide in methanol. Sections then were then heated using an autoclave in a citrate buffer $\left(0.01 \mathrm{moll}^{-1}, \mathrm{pH}\right.$ 6.5) at $121^{\circ} \mathrm{C}$ for $15 \mathrm{~min}$ to reveal the antigen. After cooling, sections were preincubated in $1 \%$ borine serum albmin (BSA) for $20 \mathrm{~min}$. Next, sections were incubated with antiosteopontin monoclonal antibody $(1: 50$, Osteopontin, Novocastra Laboratories Ltd, Newcastle, UK) for $60 \mathrm{~min}$. After rinsing with phosphatebuffered saline (PBS) for $15 \mathrm{~min}$, sections were incubated with secondary antibody for $20 \mathrm{~min}$ and washed again with PBS for $10 \mathrm{~min}$. Sections were incubated with avidin-biotin complex for $30 \mathrm{~min}$ and washed again, and reactions were visualized using diaminobenzidine tetrahydrochloride for $2 \mathrm{~min}$. All samples were lightly counterstained with haematoxylin for $1 \mathrm{~min}$. The negative controls consisted of sections treated with PBS instead of primary antibody. A section of normal tissue of gallbladder was used as positive control. Evaluation of immunohistochemistry was performed independently by two investigators (KY and SN). Positive Osteopontin expression was defined as detectable immunoreaction in perinuclear and other cytoplasmic regions of $>10 \%$ of the cancer cells. To evaluate expression of Osteopontin, 10 fields (within the tumour and at the invasive front) were selected, and expression in 1000 tumour cells (100 cells/field) was evaluated using high-power $(\times 200)$ microscopy.

\section{Statistical analysis}

Statistical analysis of group differences was performed using the $\chi^{2}$ test. The Kaplan-Meier method was used for survival analysis, and differences in survival were estimated using the log rank test. Prognostic factors were examined by univariate and multivariate analyses (Cox proportional hazards regression model). $P<0.05$ was considered to indicate statistical significance. All statistical analyses were performed using the StatView ${ }^{\mathrm{TM}}$ for Windows software (Version 5.0, Abacus Concepts, Berkeley, CA, USA).

\section{RESULTS}

\section{Expression of Osteopontin in oesophageal squamous cell} carcinoma

Osteopontin was expressed in the cytoplasm of ESCC cells in $48 \%$ (84 of 175) of all patients (Figure 1).

\section{Relationship between Osteopontin and clinicopathologic variables}

Osteopontin expression was significantly associated with the following clinicopathologic parameters: lymph node metastasis, stage and lymphatic invasion (Table 1). Patients with positive Osteopontin expression had more lymph node metastasis and greater lymphatic invasion than those with negative Osteopontin expression ( $P=0.0015$ and 0.037 , respectively).

\section{Relationship between Osteopontin expression and prognosis}

The 5-year survival rate was significantly lower in patients with positive Osteopontin expression than in those with negative Osteopontin expression $(P=0.035$; Figure 2).

\section{Univariate and multivariate analyses of survival}

Tables 2 and 3 show univariate and multivariate analyses of factors related to patient prognosis. Univariate analysis showed that the 


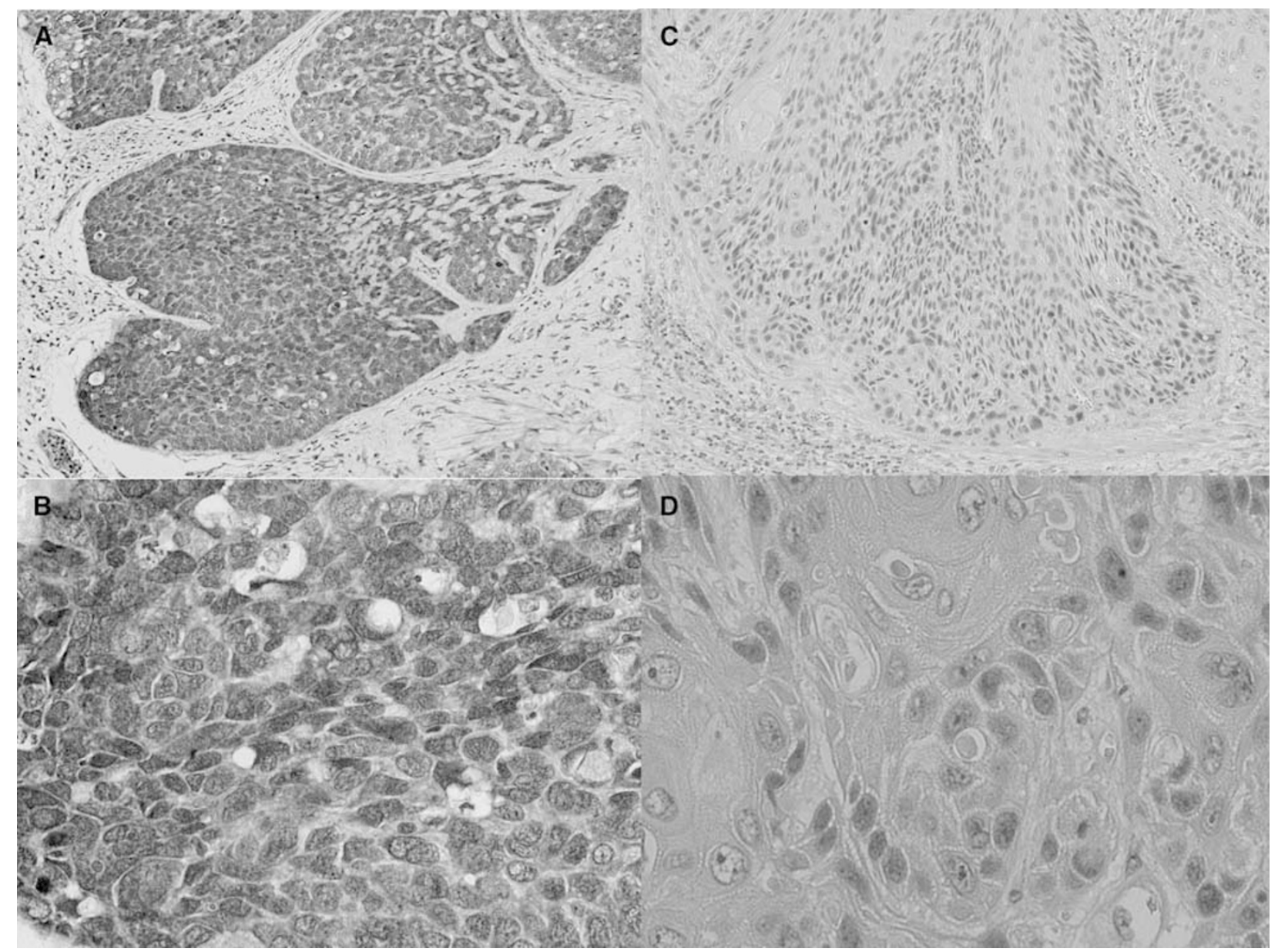

Figure I Expression of Osteopontin in ESCCs. $(\mathbf{A})$ positive expression of Osteopontin was detectable in cytoplasmic regions $(\times$ I00); $(\mathbf{B})$ magnified view $(\times 400)(\mathbf{C})$ negative expression of Osteopontin $(\times 100)$. (D) magnified view $(\times 400)$

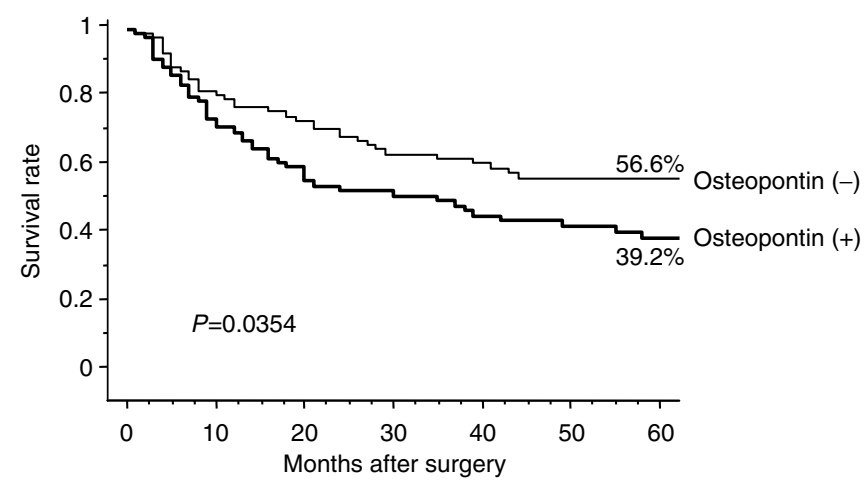

Figure 2 The postoperative 5-years survival curves between the patients expression $(-)$ and expression $(+)$ with Osteopontin. There was a significant difference between the patients with Osteopontin $(-)$ and $(+)$ expression $(P=0.0354)$.

following factors were significantly related to postoperative survival: depth of invasion and lymph node metastasis, stage, lymphatic invasion, venous invasion and Osteopontin expression $(P<0.05)$. Multivariate regression analysis indicated that depth of invasion, lymph node metastasis and venous invasion were independent prognostic factors, but that lymphatic invasion and Osteopontin expression were not independent prognostic factors.

\section{DISCUSSION}

In this study, we immunohistochemically investigated the relationship between Osteopontin expression and clinicopathological factors, including prognosis, in ESCC. The expression of Osteopontin was observed in $48 \%$ of tumours. This was consistent with previous immunohistochemical studies on other carcinomas in which Osteopontin expression was detected in $33.3-70.0 \%$ (Ue et al, 1998; Zhang et al, 2001; Coppola et al, 2004).

In the present study, Osteopontin expression was significantly associated with lymph node metastasis and lymphatic invasion. In non-small cell lung cancer, the expression of Osteopontin in surgical specimens is significantly correlated with tumour size, lymph node metastasis and stage (Donati et al, 2005). In the ESCC, plasma Osteopontin was associated with lymph node metastasis (Shimada et al, 2005). In gastric cancer, the expression of Osteopontin in poorly differentiated tumours is also associated with lymphogenous metastasis (Ue et al, 1998). Taking these results together, it appears that the expression of Osteopontin in some human malignant tumours might be more associated with metastasis than with tumorigenesis.

The molecular mechanisms that define the role of Osteopontin in tumour metastasis have not been completely elucidated, although several mechanisms have been suggested. Previous studies showed that Osteopontin can support attachment for a variety of cell types and promote migration of tumour cells (Oates et al, 1997; Tuck et al, 2000). Osteopontin contains the cell 
Table 2 Univariate analysis of prognostic factors in ESCC

\begin{tabular}{|c|c|c|c|}
\hline Variables & $n$ & $\begin{array}{c}\text { 5-years } \\
\text { survival rate } \\
(\%)\end{array}$ & $P$ \\
\hline \multicolumn{4}{|l|}{ Sex } \\
\hline Male & 160 & 80.0 & 0.0139 \\
\hline Female & 15 & 44.6 & \\
\hline \multicolumn{4}{|c|}{ Tumour depth } \\
\hline $\mathrm{pTI}, 2$ & 80 & 74.8 & $<0.0001$ \\
\hline pT3,4 & 95 & 24.3 & \\
\hline \multicolumn{4}{|c|}{ Lymph node metastasis } \\
\hline Negative & 78 & 75.4 & $<0.0001$ \\
\hline Positive & 97 & 15.8 & \\
\hline \multicolumn{4}{|l|}{ Stage } \\
\hline I, II & 93 & 75.9 & $<0.0001$ \\
\hline III, IV & 82 & 17.0 & \\
\hline \multicolumn{4}{|c|}{ Lymphatic invasion } \\
\hline Negative & 66 & 75.4 & $<0.0001$ \\
\hline Positive & 109 & 31.5 & \\
\hline \multicolumn{4}{|c|}{ Venous invasion } \\
\hline Negative & 125 & 59.8 & $<0.0001$ \\
\hline Positive & 50 & 24.7 & \\
\hline \multicolumn{4}{|l|}{ Osteopontin } \\
\hline Positive & 84 & 56.6 & 0.0354 \\
\hline Negative & 91 & 39.2 & \\
\hline
\end{tabular}

attachment amino-acid sequence RGD (arginine-glycine-aspartic acid), which bind to the alpha vs beta 3 integrin heterodimer, play a role in cell adhesion (Xuan et al, 1995). In addition, Osteopontin bind several different cellular receptors, potentially allowing it to stimulate various signalling pathways and influence cellular events that may ultimately promote tumorgenesis, adhesion, migration and metastasis (Hu et al, 1995; Liaw et al, 1995; Weber et al, 1996; Al-Shami et al, 2005). The down-stream Osteopontin signals which interrupt the cell cycle, prevent apoptosis and promote cell survival are integral to tumour progression (Evan and Vousden, 2001). There may be especially signals that corresponded with lymph node metastasis in those signals that Osteopontin stimulate. In the present study, close relationship was found between Osteopontin expression and lymph node metastasis.

Concerning the survival analysis, sex, tumour depth, lymph node metastasis, stage, lymphatic invasion, venous invasion and Osteopontin expression were prognostic factors on univariate analysis. However, multivariate analysis revealed that only tumour depth, nodal metastasis and venous invasion were independent

\section{REFERENCES}

Agrawal D, Chen T, Irby R, Quackenbush J, Chambers AF, Szabo M, Cantor A, Coppola D, Yeatman TJ (2002) Osteopontin identified as lead marker of colon cancer progression, using pooled sample expression profiling. J Natl Cancer Inst 94: 513-521

Al-Shami R, Sorensen ES, Ek-Rylander B, Andersson G, Carson DD, Farach-Carson MC (2005) Phosphorylated osteopontin promotes migration of human choriocarcinoma cells via a p70 S6 kinase-dependent pathway. J Cell Biochem 94: 1218-1233

Brown LF, Berse B, Van de Water L, Papadopoulos-Sergiou A, Perruzzi CA, Manseau EJ, Dvorak HF, Senger DR (1992) Expression and distribution of osteopontin in human tissues: widespread association with luminal epithelial surfaces. Mol Biol Cell 3: 1169-1180
Table 3 Multivariate analyses of prognostic factors in ESCC

\begin{tabular}{|c|c|c|c|}
\hline $\begin{array}{l}\text { Independent } \\
\text { factors }\end{array}$ & Multivariate $P$ & Hazard ratio & $\begin{array}{c}95 \% \\
\text { Confidence } \\
\text { interval }\end{array}$ \\
\hline \multicolumn{4}{|l|}{$p T$} \\
\hline $1,2 / 3,4$ & $<0.0001$ & 4.024 & $2.428-6.671$ \\
\hline \multicolumn{4}{|l|}{$p N$} \\
\hline Negative/positive & 0.0210 & 2.192 & $1.125-4.270$ \\
\hline \multicolumn{4}{|l|}{ Lymphatic invasion } \\
\hline Negative/positive & 0.0984 & 1.849 & $0.892-3.835$ \\
\hline \multicolumn{4}{|l|}{ Venous invasion } \\
\hline Negative/positive & 0.3005 & 1.281 & $0.802-2.046$ \\
\hline \multicolumn{4}{|l|}{ Osteopontin expression } \\
\hline Negative/positive & 0.2869 & $|.27|$ & $0.818-1.975$ \\
\hline
\end{tabular}

prognostic factors. It has previously been demonstrated that plasma Osteopontin in ESCC is associated with poor survival (Shimada et al, 2005). Expression of Osteopontin is also significantly associated with poor survival in stage I non-small cell lung cancer (Donati et al, 2005). These findings indicate that the Osteopontin overexpression in some tumours is correlated with poor prognosis, predominantly via lymph node metastasis. Although Osteopontin expression in ESCC was not found to be an independent prognostic factor in the present study, it might play an important role in promoting progression and migration to the lymphatic system. Thus, evaluation of Osteopontin expression using biopsy specimens before surgical therapy may be a new standard for appropriate lymph node dissection of ESCC.

In conclusion, we detected Osteopontin protein in ESCC and found this to be associated with lymph node metastasis, stage, lymphatic invasion, and prognosis. Osteopontin is therefore useful for predicting malignant properties. These findings suggested a possible role for Osteopontin expression level as a new diagnostic and prognostic biomarker for ESCC. Furthermore, understanding the biological function of Osteopontin expression in ESCC may help to determine its role in physiology of ESCC.

\section{ACKNOWLEDGEMENTS}

This study was supported in part by grants-in-aid for scientific research from the Ministry of Education, Science, Sports and Culture, Japan.

Brown LF, Papadopoulos-Sergiou A, Berse B, Manseau EJ, Tognazzi K, Perruzzi CA, Dvorak HF, Senger DR (1994) Osteopontin expression and distribution in human carcinomas. Am J Pathol 145: $610-623$

Coppola D, Szabo M, Boulware D, Muraca P, Alsarraj M, Chambers AF, Yeatman TJ (2004) Correlation of osteopontin protein expression and pathological stage across a wide variety of tumor histologies. Clin Cancer Res 10: $184-190$

Donati V, Boldrini L, Dell'Omodarme M, Prati MC, Faviana P, Camacci T, Lucchi M, Mussi A, Santoro M, Basolo F, Fontanini G (2005) Osteopontin expression and prognostic significance in non-small cell lung cancer. Clin Cancer Res 11: 6459-6465 
Evan GI, Vousden KH (2001) Proliferation, cell cycle and apoptosis in cancer. Nature 411: $342-348$

Giachelli CM, Steitz S (2000) Osteopontin: a versatile regulator of inflammation and biomineralization. Matrix Biol 19: 615-622

Hu DD, Lin EC, Kovach NL, Hoyer JR, Smith JW (1995) A biochemical characterization of the binding of osteopontin to integrins alpha $\mathrm{v}$ beta 1 and alpha v beta 5. J Biol Chem 270: 26232-26238

Liaw L, Skinner MP, Raines EW, Ross R, Cheresh DA, Schwartz SM, Giachelli CM (1995) The adhesive and migratory effects of osteopontin are mediated via distinct cell surface integrins. Role of alpha v beta 3 in smooth muscle cell migration to osteopontin in vitro. J Clin Invest 95: 713-724

Oates AJ, Barraclough R, Rudland PS (1997) The role of osteopontin in tumorigenesis and metastasis. Invasion Metastasis 17: 1-15

Reinholt FP, Hultenby K, Oldberg A, Heinegard D (1990) Osteopontin - a possible anchor of osteoclasts to bone. Proc Natl Acad Sci USA 87: 4473 4475

Shimada Y, Watanabe G, Kawamura J, Soma T, Okabe M, Ito T, Inoue H, Kondo M, Mori Y, Tanaka E, Imamura M (2005) Clinical significance of osteopontin in esophageal squamous cell carcinoma: comparison with common tumor markers. Oncology 68: 285-292

Sobin LH, Fleming ID (1997) TNM Classification of Malignant Tumors, fifth edition (1997) Union Internationale Contre le Cancer and the American Joint Committee on Cancer. Cancer 80: 1803-1804

Sodek J, Ganss B, McKee MD (2000) Osteopontin. Crit Rev Oral Biol Med 11: $279-303$
Thalmann GN, Sikes RA, Devoll RE, Kiefer JA, Markwalder R, Klima I, Farach-Carson CM, Studer UE, Chung LW (1999) Osteopontin: possible role in prostate cancer progression. Clin Cancer Res 5: 2271-2277

Tuck AB, Elliott BE, Hota C, Tremblay E, Chambers AF (2000) Osteopontin-induced, integrin-dependent migration of human mammary epithelial cells involves activation of the hepatocyte growth factor receptor (Met). J Cell Biochem 78: 465-475

Tuck AB, O'Malley FP, Singhal H, Harris JF, Tonkin KS, Kerkvliet N, Saad Z, Doig GS, Chambers AF (1998) Osteopontin expression in a group of lymph node negative breast cancer patients. Int J Cancer 79: $502-508$

Ue T, Yokozaki H, Kitadai Y, Yamamoto S, Yasui W, Ishikawa T, Tahara E (1998) Co-expression of osteopontin and CD44v9 in gastric cancer. Int $J$ Cancer 79: $127-132$

Varner JA, Cheresh DA (1996) Integrins and cancer. Curr Opin Cell Biol 8: $724-730$

Weber GF, Ashkar S, Glimcher MJ, Cantor H (1996) Receptor-ligand interaction between CD44 and osteopontin (Eta-1). Science 271: 509-512

Xuan JW, Hota C, Shigeyama Y, D'Errico JA, Somerman MJ, Chambers AF (1995) Site-directed mutagenesis of the arginine-glycine-aspartic acid sequence in osteopontin destroys cell adhesion and migration functions. J Cell Biochem 57: 680-690

Zhang J, Takahashi K, Takahashi F, Shimizu K, Ohshita F, Kameda Y, Maeda K, Nishio K, Fukuchi Y (2001) Differential osteopontin expression in lung cancer. Cancer Lett 171: 215-222 